\title{
How can social insurers promote return to work in occupational rehabilitation? A quantitative, cross-sectional study
}

\author{
Jarna Pasanen ${ }^{*}$ a and Arto Luoma
}

\begin{abstract}
Background: Earlier studies indicate a correlation between disability claims experience and return to work outcomes. Thus, the insurer's role and actions may affect the self-rated health of the disabled worker and the outcomes of occupational rehabilitation. This study diversifies the existing empirical evidence on the role of the insurer in the rehabilitation process and reveals the critical actions that best promote success.

Materials and methods: Explorative factor analysis (EFA) and confirmatory factor analysis (CFA), followed by binary regression, were used to analyse survey data of disabled workers $(n=661)$ who had undergone an occupational rehabilitation within an earnings-related pension insurance system in Finland.

Results: The claimant's perceptions of the insurer's (1) high-quality informing and guidance, (2) customer orientation, (3) smooth process flow and (4) positive service attitude had substantial and statistically significant effects on the success of occupational rehabilitation after adjusting for all likely confounding variables.

Conclusions: The insurer's actions are significant predictors of the outcome of occupational rehabilitation. The insurer can promote the health of rehabilitees most effectively by ensuring a smooth process flow and adopting a customer-oriented approach.
\end{abstract}

Keywords: Occupational rehabilitation, Return to work, Insurers, Disability insurance

\section{Background}

In most developed countries, public compensation systems providing support for those unable to work because of illness or injury are usually governed by public institutions or private insurance providers. Many disability insurance systems only cover injuries or illnesses if they are due to a specific cause, including workers' compensation, automobile insurance and crime victim's insurance. These systems are referred to as cause-based systems. However, there are also disability-based systems that provide sickness and disability insurance for all forms of work disability, regardless of the cause [1].

\footnotetext{
* Correspondence: jarna.pasanen@tuni.fi

Faculty of Management and Business, Tampere University, Fl-33014 Tampere, Finland
}

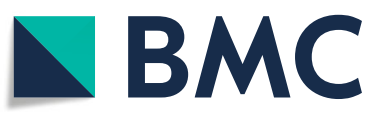

(c) The Author(s). 2021 Open Access This article is licensed under a Creative Commons Attribution 4.0 International License, which permits use, sharing, adaptation, distribution and reproduction in any medium or format, as long as you give appropriate credit to the original author(s) and the source, provide a link to the Creative Commons licence, and indicate if changes were made. The images or other third party material in this article are included in the article's Creative Commons licence, unless indicated otherwise in a credit line to the material. If material is not included in the article's Creative Commons licence and your intended use is not permitted by statutory regulation or exceeds the permitted use, you will need to obtain permission directly from the copyright holder. To view a copy of this licence, visit http://creativecommons.org/licenses/by/4.0/ The Creative Commons Public Domain Dedication waiver (http://creativecommons.org/publicdomain/zero/1.0/) applies to the data made available in this article, unless otherwise stated in a credit line to the data. nations when it comes to public disability insurance systems, they still have common features regarding the compensation process and the role of the administrative body (whether it is a public social insurance agency or private insurance company). This organisation is usually responsible for the compensations and it interacts with all the stakeholders involved in the rehabilitation and return to work process [1-3].

Today, the return to work (RTW) process after an illness or injury is understood as a biopsychosocial phenomenon [4]. This means that biological, psychological and social factors related to the personal, work, healthcare and insurance domains influence the course and outcome of rehabilitation [5]. Thus, the role and 
actions of rehabilitation stakeholders are seen vital to the outcomes of the process. Occupational rehabilitation stakeholders are usually categorized from system theory perspective into three main groups: employers (work system), healthcare providers (health system) and insurance (insurance system). Previous studies suggest that these stakeholders' actions may affect the outcomes of the rehabilitation [6-8]. Our study focuses on the insurer's actions (more specifically guidance, customerorientation, process flow and service attitude among the insurer's representatives) and their connection to successful rehabilitation.

Current theories suggest that more positive relationships between the insurer and claimants may improve the worker's chance of recovery $[9,10]$ and vice versa. Qualitative studies focusing on relationships between disabled workers and healthcare or insurance officials highlight the importance of mutual trust, respect, and credibility [11, 12]. Furthermore, high-quality informing, professional expertise, a supportive and individual approach, a personal relationship with officials, participation in decisionmaking and individually chosen rehabilitation measures and goals are mentioned as promoters of RTW [12-15]. Quantitative studies [16-21] support the hypothesis of a causal relationship between insurer actions and the outcomes of occupational rehabilitation. Within a worker's compensation system, the high stress levels from encounters with insurers were positively correlated with poor long-term recovery of injured workers [18] whereas a positive claims experience was strongly associated with having returned to work [3].

The results are similar between sick-listed individuals and social insurance officials in disability-based insurance schemes. Negative encounters with social insurance officers are negatively correlated with self-rated health, self-rated ability to work and mood, whereas positive encounters with social insurers facilitate RTW [17, 19-21].

As shown above, there is some evidence indicating a connection between insurer actions and the probability of RTW. However, there is a need for further evidence and a more comprehensive understanding of the insurer's role and the specific actions that best support the health of disabled workers and promote RTW. While the earlier quantitative studies have concentrated on sick-listed patients or work injury victims, this article focuses on occupational rehabilitees, thus enlarging the scope and providing useful information to all rehabilitation stakeholders. Here, we do not collapse groups of stakeholders together (as e.g. in [16, 22]), but only examine the role of the insurer in order to eliminate the confounding factors related to other stakeholders. Our survey data enable a definition of dimensions related to the insurer's role and their comparison with respect to RTW outcomes. The aims of this study are (1) to investigate the connection between insurer actions and the results of occupational rehabilitation, and (2) to explore which insurer actions best promote occupational rehabilitation success. Our research hypotheses, from the weakest (or least specific) to the strongest (most specific), are as follows:

\section{H1: Claimant's perceptions of insurer actions during} occupational rehabilitation are related to the outcome of rehabilitation.

H2: Claimant's perceptions of positive insurer actions, including high-quality informing, supportive service attitude and individual approach, are positively related to successful occupational rehabilitation.

H3: The positive relationship between the claimant's perceptions of positive insurer actions and successful occupational rehabilitation remains even if an adjustment is made for all likely confounding variables.

\section{Methods}

This section presents the key elements of the study design, describes the research setting and participants, defines the used variables, their handling and measurement and presents the statistical methods. Here, we follow the STROBE statement [23].

\section{Study design}

We used a cross-sectional survey design to investigate the connection between the claimant's perceptions of insurer actions and the outcome of occupational rehabilitation. The study population included all private sector wage earners ${ }^{1}$ whose occupational rehabilitation process involved a service provider and whose rehabilitation case was closed in 2015. The rehabilitee's case is closed in the online system when there is no further need for a service provider in the rehabilitation process. The main reason for this is that the rehabilitation assessments, plans for rehabilitation measures and all preparations needed to start the rehabilitation (e.g. finding an internship or student place) have been made. However, the rehabilitation measures themselves (such as retraining for an occupation) and the contact with the insurer often continue after this stage. Another reason for a closed case is the cancellation of occupational rehabilitation due to any reason, such as significant deterioration of the disability or other change in rehabilitation conditions.

The cross-sectional data were collected in 2017, about 2 years after the claimant's rehabilitation case had been closed in the web service. This point of time was chosen because the occupational

\footnotetext{
${ }^{1}$ Private sector wage earners are insured according to the Employees Pensions Act (TyEL) and constitute almost 70\% of all wage earners in Finland [24].
} 
rehabilitation would probably be over by then for most claimants, and its outcome would be known. On the other hand, not too much time would have passed after the rehabilitation so that the claimants could still remember the insurer's actions during the process.

\section{Setting and participants}

The study sample was obtained from KuntoutuNET, a Finnish online service for the processing and maintenance of customer data about occupational rehabilitation. This service is used as a communication tool between the subscribers (all private sector pension institutions) and producers of rehabilitation services (e.g. institutions, companies, communities, and healthcare units providing vocational rehabilitation services). The insurers may choose to use service providers to assist in the planning and execution of occupational rehabilitation within an earnings-related pension scheme in Finland. According to the Service Network of Occupational Rehabilitation (2016), service providers are used to assist in the settling and planning of occupational rehabilitation when the application for rehabilitation compensation lacks a rehabilitation plan, employment or work trials in a former or current workplace are not possible or when the rehabilitee needs close guidance. The service providers are also used to assess the rehabilitee's abilities and opportunities for employment or studying [25].

The sample consisted of 2264 individuals and included all rehabilitees whose cases were closed in the KuntoutuNET online service in 2015. The data acquired from KuntoutuNET included the rehabilitee's identification number, age, gender, and contact details (phone number and/or email-address). An online questionnaire was sent to the respondents on June 6, 2017, and reminder messages were delivered on June 13 and June 20, 2017. The data were collected using a text message and an e-mail survey. The survey was sent by e-mail to a total of 836 people whose e-mail addresses were stored in the KuntoutuNET online service. In addition, the survey was sent by text message to 1428 people, for whom only a telephone number was available.

\section{Variables and measurement}

We took into account earlier empirical findings and considered potential effects of insurer actions on RTW outcomes when designing the questionnaire. In addition to questions related to sociodemographic variables and the process and outcomes of occupational rehabilitation, the questionnaire included altogether 26 propositions concerning the actions of the insurers and rehabilitation service providers. These propositions were formed on the basis of earlier studies [3, 7, 12-22], and the key terms were translated from English to Finnish by the authors. The questions were answered on a 5-point Likert scale with responses ranging from 1 (strongly disagree) to 5 (strongly agree). The sixth alternative, "doesn't concern me" was coded as a missing value. Since our focus was on the actions of the insurer, we excluded from the analysis the questions purely related to the actions of rehabilitation service providers and ended up with 17 insurer-related propositions (listed as part of Table 4 in the Results section).

To isolate the effect of insurer actions, we included several potential confounding factors in our regression models, for example age, employment situation before rehabilitation, level of education, occupation, monthly net income and cause of rehabilitation. Age was included as a continuous variable and employment situation before rehabilitation as a dichotomic variable. The level of education was grouped into six categories: primary school, secondary school, vocational college, general upper secondary school, and university. The occupation had also six categories: employee, lower official, senior officer, leading position, entrepreneur, and agricultural entrepreneur. The cause of rehabilitation had three categories: musculoskeletal diseases, mental disorders and other causes; and monthly net income had six categories: below 500 euros, 500-999 euros, 1000-1499 euros, 1500-2499 euros, 2500-3999 euros, over 4000 euros.

Furthermore, we included the respondent's motivation and the objectives of rehabilitation as possible confounding factors in our regression models. Motivation was measured on a 5-point Likert scale, the response alternatives ranging from 1 (not at all motivated) to 5 (extremely motivated). In addition, the questionnaire included six preformulated objectives for occupational rehabilitation: (1) return to work, (2) more suitable profession, (3) new job in earlier workplace, (4) improvement of professional capabilities, (5) improvement of mental well-being and (6) receiving a disability pension. The respondents were once more asked to use a 5-point Likert scale ranging from 1 (not at all important) to 5 (extremely important) to rate how important these objectives were to them before starting the process. Similar classifications regarding the motivation and objectives of rehabilitation have been used, for example, by Gould et al. [26].

The most frequently used measures of rehabilitation outcomes are self-rated health or self-rated ability to return to work (e.g. $[17,19,20])$ and employment status after rehabilitation (return to work) (e.g. [27, 28]). Here, we were able to use both measures. The respondents self-assessed their ability to work at the time of answering on a scale of 4 (totally unable to work) to 10 (excellent), which corresponds to the Finnish school rating scale and was therefore considered to be easily 
understood. ${ }^{2}$ In addition, the respondents were asked whether they had returned to work after the rehabilitation or not.

The employment status after rehabilitation was not an ideal measure of rehabilitation success in our study, since the RTW rate was only $30 \%$ and a significant amount of respondents were still in rehabilitation (for example, education leading to a degree may take several years to complete) or unemployed. Therefore, we formed a binary indicator of rehabilitation success by combining the self-rated ability to work and return to work variables. The rehabilitation was regarded as successful if the respondent had fully returned to work successfully or if the self-rated ability to work was 7 (satisfactory) or higher. We considered the objective of occupational rehabilitation (to improve the chances of a disabled individual to earn income in the future and to prevent permanent disability) to have been achieved in these situations.

\section{Statistical methods}

Since our aim was to explore the connections between insurer actions and successful rehabilitation, we decided to use factor analysis to determine the dimensions of the insurer's role, and binary regression to explain the result of rehabilitation by factor scores. There were 661 observations which had responses in the relevant variables, and in 108 cases some of the variables had missing values. To include these partially missing observations, we used the full information maximum likelihood (FIML) method.

The factor analysis was conducted in two steps: First, exploratory factor analysis (EFA) was used to determine the constructs or factors which best explain the observed correlations structure of the indicator variables, and, second, confirmatory factor analysis (CFA) was used to check the adequacy of the adopted factor model.

In the explorative analysis we used principal-axis factoring (PAF) since the data were not normally distributed. According to Fabrigar, Wegener, MacCallum and Strahan [29], the principal factor methods are the best choice if the assumption of multivariate normality is "severely violated" [30]. In our case, the responses were measured with the Likert scale, and had high means leading to negative skewness. However, the skewness went beyond the recommended limits of -1.00 or 1.00 [30] only for two variables (PF1 and SA1; see Table 3), and even for them it was not very high $(>3)$.

Further, since the sample size was fairly large (549 observations after listwise deletion of missing data) and the

${ }^{2}$ Historically, the Finnish school grading system had a scale of 0 to 10 , but all grades lower than 4 were consolidated into one failing grade of 4 in 1952. results of EFA were almost identical to those obtained by the maximum likelihood estimation (MLE) method, we are confident that the results of CFA, which are based on the assumption of multivariate normality, are sufficiently accurate. Further, since the factors were obviously correlated, we used the promax rotation, which allows for such correlation. For EFA, we provide the factor loadings, means, standard deviations, Cronbach's alphas, and average variance extracted (AVE) and construct reliability $(\mathrm{CR})$ statistics for each measured item in Table 3.

In CFA, we first fitted a model corresponding to that from EFA. The resulting factor scores were used as independent variables in a logistic regression model explaining the success of rehabilitation. However, since the factor effects were ambiguous due to high factor correlation, we fitted another confirmatory factor model with independent factors (labeled as from $\mathrm{F}_{1}$ to $\mathrm{F}_{4}$ ) in order to separate the effects of the factors and to have a parsimonious correlation structure.

This model was not very well-fitting, so we added one further factor (labeled as G) to account for the correlations between the variable groups representing the independent factors. Factor $\mathrm{G}$ would represent the individual effect of the respondents, that is, their tendency to answer in a similar way to all questions. The factor loadings of $\mathrm{G}$ on all indicators were set to be equal. Further, since factor $\mathrm{F}_{4}$ had only two indicators, its loadings were also set equal to each other to make the model identifiable.

In the next step, factor scores were computed using the regression method. It turned out that the distribution of the scores of factor G had a long-left tail (Fig. 1). However, this should not pose a problem since the regression method is based on the correlation structure of the variables and does not require the indicators or the factors to be normally distributed. Finally, logistic

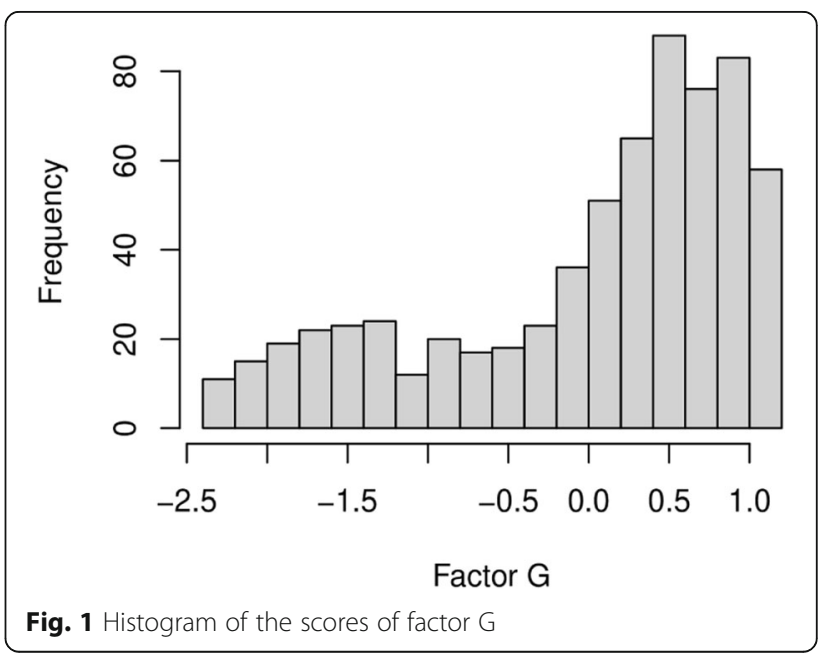


regression was used to regress the response variable on the factor scores. Probit regression yielded comparable results, but the fit of the logistic model was slightly better.

We also studied whether the connection between the insurer's actions and the outcome of occupational rehabilitation could be explained by confounding variables. We added several likely confounding factors in our logistic regression model, including gender, age, level of education, employment situation, occupation, monthly net income, cause of rehabilitation, motivation and rehabilitation objectives. The demographics were computed and the explorative factor analyses conducted using the SPSS Version 26.0 for Windows; the CFA was run using the package lavaan (Rosseel, 2012) of the $R$ software ( $\mathrm{R}$ Core Team, 2020), and the logistic regression using the $\mathrm{R}$ function glm.

\section{Results}

The response rate of the survey was 29\% $(n=661)$. Table 1 shows that the proportion of respondents was higher in women than in men and slightly higher in younger people than in elderly.

Table 2 displays the basic characteristics of the respondents. The age range was 25-63 years, with a median age of 48. Most respondents were male (52\%), had a vocational qualification $(68 \%)$ and suffered from musculoskeletal diseases (66\%). With the binary indicator of rehabilitation success (combining the self-rated ability to work and return to work variables), occupational rehabilitation proved successful for $60 \%(n=395)$ of the respondents.

We conducted an explorative factor analysis (EFA) with four common factors for the 17 insurer related propositions. All these items exhibited sufficient factor loadings and communalities $(>.50)$ and were retained for further analysis. The four factors accounted for $93.37 \%$ of the total variance, and each factor explained at least $4.34 \%$ of the total variance, fulfilling the minimal requirements presented by Netemeyer et al. [31]. Table 3 shows the estimated factor loadings, means and standard deviations of each measured item. Further, Cronbach's alphas, and average variance extracted (AVE) and construct reliability (CR) statistics are provided for each factor. The four dimensions of the insurer's role, their measures in the questionnaire and item codes are shown in Table 4. The propositions in Table 4 were translated from Finnish by the authors; these survey questions can be found in the original language in the appendix.

The first factor is theorized to represent informing and guidance during the rehabilitation process (variables IG1-IG6), the second factor is related to customer oriented approach (variables CO1-CO5), the third factor describes the process flow (variables PF1- PF4), and the fourth factor indicates the service attitude of the insurance personnel (variables SA1-SA2). Altogether, the sizes of the factor loadings (all above .8), AVE measurements (all above .8), and CR scores (all above .9) lend support to the convergent validity of each scale.

Next, we conducted a confirmatory factor analysis (CFA) based on the results above. We first fitted a model with a free factor correlation structure and zero restrictions on factor loadings as indicated by EFA. The model fit was good $(\mathrm{CFI}=0.990, \quad \mathrm{SRMR}=0.014, \quad \mathrm{RMSEA}=$ 0.046) although the hypothesis of perfect fit was rejected $\left(\mathrm{X}^{2}=310.8, \mathrm{df}=130, p=.000\right)$. When the resulting factor scores were used as independent variables in a logistic regression model explaining the success of rehabilitation, we could find support for hypothesis $\mathrm{H}_{1}$, which states that the claimant's perceptions of insurer actions during occupational rehabilitation are related to the outcome of rehabilitation.

However, since it was not possible to separate the effects of the factors due to high factor correlations (ranging from 0.548 to 0.746 ), we fitted another model with uncorrelated factors. The model had an inferior and inadequate fit $\left(\chi^{2}=1823.5, \mathrm{df}=137, p=.000\right.$; CFI $=0.906$, SRMR $=0.496$, RMSEA $=0.136$ ). Finally, we fitted a factor model, with four independent factors as indicated by $\mathrm{EFA}$, and one further independent factor accounting for the individual effect and correlation between the variable groups. The fit was almost as good as in the first case

Table 1 Descriptives of the respondents in relation to the intended sample

\begin{tabular}{llll}
\hline & Respondents $(\mathbf{n})$ & Intended sample $(\mathbf{n})$ & Response rate by gender and age $(\%)$ \\
\hline $\begin{array}{lll}\text { Gender } \\
\text { female }\end{array}$ & & & $35 \%$ \\
male & 314 & 898 & $25 \%$ \\
Age & 347 & 1366 & \\
$25-34$ & & & $31 \%$ \\
$35-44$ & 62 & 201 & $33 \%$ \\
$45-54$ & 177 & 538 & $29 \%$ \\
$55-63$ & 257 & 881 & $26 \%$ \\
\hline
\end{tabular}


Table 2 Basic characteristics of the respondents

\begin{tabular}{|c|c|}
\hline & $\%$ \\
\hline \multicolumn{2}{|l|}{ Gender } \\
\hline female & 48,0 \\
\hline male & 52,0 \\
\hline \multicolumn{2}{|l|}{ Age } \\
\hline $25-34$ & 9,3 \\
\hline $35-44$ & 27,0 \\
\hline $45-54$ & 39,0 \\
\hline $55-63$ & 24,7 \\
\hline \multicolumn{2}{|l|}{ Level of education } \\
\hline primary school & 2,4 \\
\hline secondary school & 13,4 \\
\hline vocational college & 68,4 \\
\hline general upper secondary school & 6,8 \\
\hline university of applied sciences & 3,8 \\
\hline university & 5,2 \\
\hline \multicolumn{2}{|l|}{ Monthly net income $(€)$} \\
\hline $0-499$ & 1,2 \\
\hline 500-999 & 13,4 \\
\hline $1000-1499$ & 23,7 \\
\hline $1500-2499$ & 44,5 \\
\hline 2500-3999 & 14,5 \\
\hline $4000-$ & 2,6 \\
\hline \multicolumn{2}{|l|}{ Cause of rehabilitation } \\
\hline Musculoskeletal diseases & 66,4 \\
\hline Mental disorders & 13,4 \\
\hline Other cause & 20,2 \\
\hline \multicolumn{2}{|c|}{ Life situation at the time of the survey } \\
\hline Rehabilitation ongoing & 15,2 \\
\hline Successful RTW & 30,1 \\
\hline Unemployed & 20,9 \\
\hline Unable to work & 27,1 \\
\hline Other situation & 6,7 \\
\hline \multicolumn{2}{|c|}{ Self-rated ability to work at the time of the survey } \\
\hline Poor (grade 4) & 18,9 \\
\hline Tolerable (grades 5 to 6) & 23,7 \\
\hline Good (grades 7 to 8) & 41,4 \\
\hline Very good (grades 9 to 10) & 16,0 \\
\hline \multicolumn{2}{|c|}{ Rehabilitation outcome (binary variable) } \\
\hline Success & 59,6 \\
\hline Failure & 40,4 \\
\hline
\end{tabular}

$\left(\mathrm{X}^{2}=390.2, \mathrm{df}=136, p=.000 ; \mathrm{CFI}=0.986 ; \mathrm{SRMR}=0.060 ;\right.$ RMSEA $=0.053)$. The items' squared multiple correlations (SMCs) ranged from 0.853 to 0.945 .
Then, factor scores were computed using the regression method. These scores, excluding the individual effect score, were used as independent variables in a logistic regression model explaining the success of rehabilitation. Figure 2 shows the path coefficients for all the relationships in our two-stage model. All coefficients are statistically significant at the 0.001 level. The coefficients of the factor measurement model are standardized. The results suggest that the insurer's customer oriented approach $(\beta=3.84)$ and smooth process flow $(\beta=3.27)$ have the highest impact on the success of occupational rehabilitation, but also proper informing and guidance $(\beta=2.32)$ and positive service attitude $(\beta=$ 0.89 ) are associated with positive rehabilitation outcomes. The pseudo- $\mathrm{R}^{2}$ values (McFadden $=0.503$, Cox and Snell $=0.490$, Nagelkerke $=0.664$ ) all indicate excellent model fit. Obviously, this result supports our research hypothesis $\mathrm{H}_{2}$, which states that the claimant's perceptions of positive insurer actions are positively related to successful occupational rehabilitation.

We also studied whether these results could be explained by confounding variables (gender, age, level of education, employment situation, occupation, monthly net income, cause of rehabilitation, motivation and rehabilitation objectives), which are background variables affecting both the independent variables and the outcome variable. We found that age, self-rated ability to work before rehabilitation, motivation, and the objectives of either professional development or receiving disability pension, along with the insurer factors, were statistically significant predictors of the rehabilitation outcome. Table 5 shows that the inclusion of these explanatory variables slightly decreased the effect estimates of the insurer factors but did not render them statistically insignificant. The pseudo- $\mathrm{R}^{2}$ values improved (McFadden = 0.579, Cox and Snell $=0.538$, Nagelkerke $=0.730$ ). The number of included observations was 608 . Thus, we find support for the research hypothesis $\mathrm{H}_{3}$, according to which the positive relationship between the claimant's perceptions of positive insurer actions and successful occupational rehabilitation remains even if an adjustment is made for all likely confounding variables.

\section{Discussion}

Our purpose was to explore the connection between the insurer's actions and the outcome of occupational rehabilitation. Factor scores measuring the dimensions of the insurer's role were used as independent variables in a binary regression model explaining the success of rehabilitation. According to earlier studies, positive encounters with insurers improve the worker's chance of recovery after an illness or injury and vice versa $[9,10]$. Our results confirm these earlier perceptions and enlarge evidence-based understanding of the effects of 
Table 3 Results of EFA

\begin{tabular}{|c|c|c|c|c|c|c|c|c|c|}
\hline Item & Mean & Standard deviation & Crohn-bach's alpha & Factor 1 & Factor 2 & Factor 3 & Factor 4 & CR & AVE \\
\hline IGI & 3.54 & 1.38 & 0.983 & 0.912 & & & & {$[.969]$} & {$[.842]$} \\
\hline IG2 & 3.46 & 1.36 & & 0.974 & & & & & \\
\hline IG3 & 3.71 & 1.35 & & 0.910 & & & & & \\
\hline IG4 & 3.70 & 1.33 & & 0.876 & & & & & \\
\hline IG5 & 3.64 & 1.33 & & 0.914 & & & & & \\
\hline IG6 & 3.50 & 1.35 & & 0.917 & & & & & \\
\hline $\mathrm{CO} 1$ & 3.39 & 1.44 & 0.984 & & 0.892 & & & {$[.972]$} & [.878] \\
\hline $\mathrm{CO} 2$ & 3.72 & 1.31 & & & 0.926 & & & & \\
\hline $\mathrm{CO} 3$ & 3.66 & 1.37 & & & 0.969 & & & & \\
\hline $\mathrm{CO} 4$ & 3.59 & 1.35 & & & 0.967 & & & & \\
\hline $\operatorname{co5}$ & 3.70 & 1.35 & & & 0.929 & & & & \\
\hline PF1 & 4.01 & 1.27 & 0.972 & & & 0.894 & & {$[.943]$} & {$[.807]$} \\
\hline PF2 & 3.85 & 1.23 & & & & 0.933 & & & \\
\hline PF3 & 3.81 & 1.35 & & & & 0.927 & & & \\
\hline PF4 & 3.78 & 1.26 & & & & 0.835 & & & \\
\hline SA1 & 4.04 & 1.20 & 0.953 & & & & 0.973 & {$[.907]$} & [.832] \\
\hline SA2 & 3.49 & 1.32 & & & & & 0.847 & & \\
\hline
\end{tabular}

insurer actions on the outcomes of occupational rehabilitation. This study contributes to the literature by identifying the different dimensions of the insurer's role, confirming the connection between insurer actions and successful occupational rehabilitation and by revealing which actions best promote success.

Our results illustrate the multidimensional nature of the insurer's role. Exploratory factor analysis suggested four dimensions for insurer actions. This was tested using confirmatory factor analysis, and factor scores from our final confirmatory model were used as input in a binary regression model. The first objective of the study was to examine the possible connection between insurer actions and the outcome of occupational rehabilitation. According to the research hypotheses, this type of connection would exist $\left(\mathrm{H}_{1}\right)$, the claimant's

Table 4 Dimensions of the insurer role and their measures in the questionnaire

\begin{tabular}{|c|c|c|}
\hline Insurer role -dimensions & Measure & Item code \\
\hline \multirow[t]{6}{*}{ Informing and guidance } & I received sufficient information from the insurer & $\mid \mathrm{G} 1$ \\
\hline & The insurer's instructions, announcements and information were clear and understandable & IG2 \\
\hline & I received expert service from the insurer & IG3 \\
\hline & The insurer's staff were easily accessible & IG4 \\
\hline & The different rehabilitation options were adequately discussed & IG5 \\
\hline & I received sufficient information at all stages of the rehabilitation process & IG6 \\
\hline \multirow[t]{5}{*}{ Customer orientation } & The insurer considered my personal situation and individual needs & CO1 \\
\hline & The return to work plan reflected my own views and aspirations & $\mathrm{CO} 2$ \\
\hline & The return to work plan was feasible & $\mathrm{CO} 3$ \\
\hline & The content of the rehabilitation met my needs & $\mathrm{CO} 4$ \\
\hline & I had the opportunity to influence the rehabilitation process & CO5 \\
\hline \multirow[t]{4}{*}{ Process flow } & I was satisfied with the insurer's compensation decision regarding rehabilitation & PF1 \\
\hline & The insurer started the settlement of rehabilitation at an appropriate time. & PF2 \\
\hline & The insurer carried out the rehabilitation measures quickly enough & PF3 \\
\hline & The rehabilitation process proceeded on schedule & PF4 \\
\hline \multirow[t]{2}{*}{ Service attitude } & The insurer's customer service was friendly & SA1 \\
\hline & The insurer sought to highlight the positive aspects and opportunities & SA2 \\
\hline
\end{tabular}




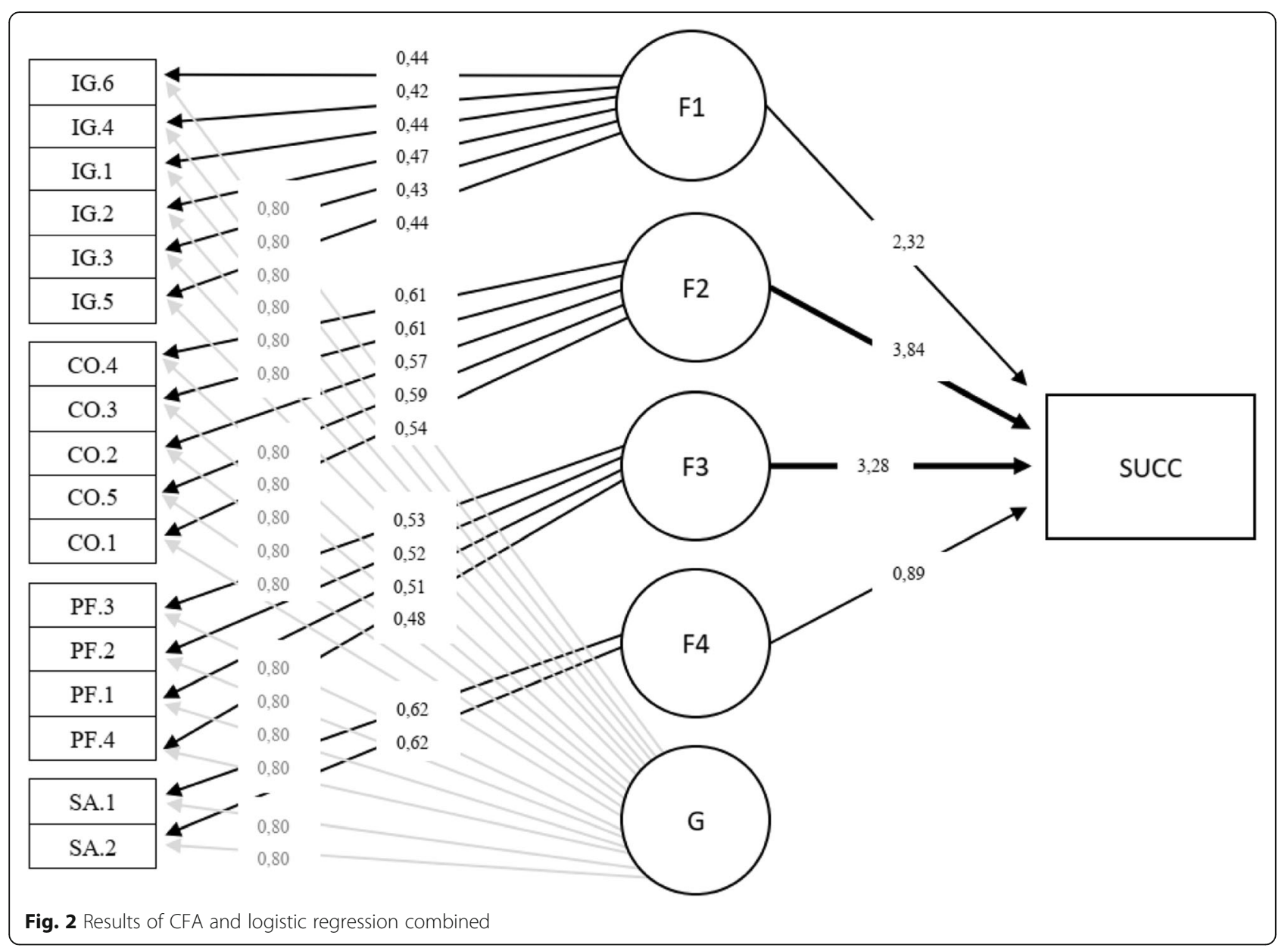

perceptions of positive insurer actions would be positively related to the success $\left(\mathrm{H}_{2}\right)$ and the positive relationship would remain even if an adjustment was made for all likely confounding variables $\left(\mathrm{H}_{3}\right)$. All these hypotheses were supported. The second objective of the study was to explore which insurer actions best promote success.

Table $\mathbf{5}$ Logistic regression model for the successful rehabilitation outcome

\begin{tabular}{lll}
\hline Explanatory variable or factor & Coefficient & z-value \\
\hline F1 - Informing and guidance & $1.96^{* * *}$ & 6.03 \\
F2 - Customer orientation & $3.46^{* * *}$ & 9.85 \\
F3 - Process flow & $3.10^{* * *}$ & 8.87 \\
F4 - Service attitude & $0.654^{*}$ & 2.36 \\
Age & $-0.042^{*}$ & -2.34 \\
SRH before rehabilitation & $0.258^{*}$ & 2.41 \\
Motivation & $0.405^{*}$ & 2.19 \\
Objective: professional development & $0.399^{* *}$ & 2.93 \\
Objective: receiving disability pension & $-0.355^{* * *}$ & -3.60 \\
\hline
\end{tabular}

Signif. Codes: 0 **** $0.001^{* * * \prime} 0.01 * 0.05$ '. 0.1 “ 1
To test these hypotheses, we first used factor analysis to determine the dimensions of the insurer's role. We came to four dimensions: (1) informing and guidance, (2) customer orientation, (3) process flow and (4) service attitude. Second, we used binary regression to explain the result of rehabilitation by factor scores. The results showed that sufficient, adequate, accessible, understandable, and professional informing and guidance is one significant factor promoting a positive outcome of rehabilitation. The importance of high-quality information and professional expertise has been brought up by various scholars [13, 32], and our results support and validate these previous findings.

The insurer's customer-oriented approach, which includes paying attention to customer needs and involving customers in the planning and decision-making processes, had a significant positive effect on the outcome of rehabilitation. While the importance of customeroriented approach has been highlighted in previous studies [7, 27, 32], our study suggests that changing the claimant's role from a passive object to an active player is the most effective way for the insurer to promote success. Thus, customer-orientation should be highlighted 
in policy design, and new ways of making the claimants participate in the design and implementation of the rehabilitation process should be developed.

Several authors report friction between injured workers and insurers caused by delays in claims handling or claims manipulation [10,33,34], which can be expected to have a negative impact on the return-towork process. Besides discrepancies in the compensation process, the wrong timing of rehabilitation has also proven to be harmful to a successful return to work [28, $35,36]$ and vice versa. In accordance with these earlier results, the present study showed that a smooth process flow, including effective claims handling, justified decisions and timely actions, had a significant positive effect on the success of rehabilitation. This effect was considerably large, and alongside the customer-oriented approach, the smooth process flow seems to be one of the most important ways for insurers to contribute to successful rehabilitation. Thus, insurers would benefit from developing the compensation and rehabilitation processes as efficient and consistent as possible. Designated case managers within an insurance company could also improve the process flow.

Earlier studies have reported both negative [32, 33] and positive $[14,16,37]$ experiences related to the insurer's customer service. Olsson et al. [21] showed that supportive, encouraging and kind service was significantly associated with promoting the ability to RTW. We found that the service attitude factor had a small, but positive and statistically significant effect on the success of rehabilitation. However, it is noteworthy that the original variable relating to the kindness of service was highly skewed (-1.163), indicating that the majority of the respondents received friendly service.

We also tested whether confounding variables could explain the connection between insurer actions and the rehabilitation outcome. The results showed that besides insurer actions, also age, self-rated ability to work before rehabilitation, motivation and rehabilitation objectives were statistically significant predictors of the rehabilitation outcome. When adjusting for potential confounding variables, all insurer factors remained statistically significant and the changes in the regression coefficients were minor.

\section{Research limitations and reliability}

The questionnaire was created purely for this study. It was built and the hypotheses were formulated on the basis of previous literature. However, there were limitations concerning the development and testing of models. First, the questionnaire was part of a larger survey related to the functioning of occupational rehabilitation. Thus, the focus of the researchers or respondents was not limited to this instrument. Second, the questionnaire had not been used or tested before. However, it was reviewed by external researchers and the steering group of the rehabilitation service network. After receiving feedback, the comments were evaluated, and the questionnaire was revised.

The empirical testing was based on cross-sectional data gathered after occupational rehabilitation. Thus, memory errors and opinion changes are possible, which should be considered when interpreting the results. Furthermore, the Likert scale-based answer options of the survey questions might have been interpreted differently by the respondents. This tendency of giving systematically better or worse assessments on every question was taken into account in our final model by adding an individual effect factor (G). All criteria set for the validity of the factor model were met and all the hypotheses were supported by the data. In addition, the developed model helped verify the results of the earlier studies.

The other factors undermining the reliability of the research are related to the representativeness and suitability of the research data and the reliability of the used methods. The final data set included 661 respondents and the response rate was $29 \%$, which is quite typical of an online survey. In surveys, non-response always occurs, and it is difficult to set unambiguous criteria for acceptable loss. Yet, non-response bias and representation of the population of interest should be evaluated. Table 1 shows the differences between the whole sample and the respondents. Although the proportion of respondents was higher in women than in men and higher in younger people than in elderly, the differences in gender and age between the respondents and those in the intended sample were minor. Thus, in the light of these variables, we consider that the respondents represent the whole sample at a satisfactory level.

Regarding the representation of the population of interest, we compared our actual sample to the population of all rehabilitees within an earnings-related pension in Finland in 2015 [38]. The distributions of the basic characteristics (age, gender, cause of disability) were quite similar, the main differences being that men and those suffering from musculoskeletal disorders were slightly over-represented in our sample, and those suffering from mental disorders were slightly underrepresented.

However, the respondents could vary from these populations on an innumerable number of other factors that have not been tested. One major consideration is that our study sample only included rehabilitees who had a contact with a rehabilitation service provider. This choice is not random: a service provider is not usually involved in cases which are straightforward or easy to carry through. Therefore, our results may not fully generalize to a wider population of disabled workers. 
Regarding the actual sample size, it can be considered sufficient for the methods used. Musil et al. [39] suggested that a structural equation model (SEM) analysis should have at least five observations for each variable. This condition was well fulfilled. However, it is a limitation that EFA and CFA were performed using the same data. Ideally, the factor model suggested by EFA would be tested with a new data set. In any case, there is a need to continue developing the model and to test its validity with different data.

Finally, the path coefficients in our two-stage model (in Fig. 2) should be interpreted with caution. Although the model is presented as a path diagram, and it is highly probable that there are causal links between insurer actions and the outcome of the rehabilitation, we do not consider the coefficients to be unbiased estimates of the actual causal effects. The reason is that the rehabilitee evaluated the performance of the insurer and the outcome of the rehabilitation at the same time, so that that feedback effects are likely to bias the estimates. Rather, the coefficients indicate the strength of association, or correlation, between the factors and the outcome of rehabilitation.

\section{Conclusions}

Our results suggest that the insurer's actions are substantially associated with the outcome of occupational rehabilitation. These findings support and confirm previous research results and help assess the relative importance of different actions by providing effect estimates for them. As for practical implications, the study reveals that the insurer would benefit most from ensuring a smooth process flow and adopting a customer-oriented approach, since they are the most important insurerrelated determinants of successful occupational rehabilitation.

\section{Supplementary Information}

The online version contains supplementary material available at https://doi. org/10.1186/s12889-021-11758-w.

\section{Additional file 1.}

\section{Acknowledgements}

We thank Professor Lasse Koskinen (Tampere University) for his encouraging support and valuable comments during the article writing process. We also thank the anonymous referees for their insightful questions and useful suggestions.

\section{Authors' contributions}

JP designed and conducted the survey and performed the initial data analyses. Furthermore, JP was the principal contributor in writing the manuscript. AL contributed to data analysis, interpretation of results and writing the manuscript. Both authors read and approved the final manuscript.

\section{Funding}

No funding was received for the research reported.

\section{Availability of data and materials}

The datasets used and/or analysed during the current study are available from the corresponding author on reasonable request.

\section{Declarations}

\section{Ethics approval and consent to participate}

According to the Finnish national board on research integrity (TENK) ethical approval for such study is not required. Informed consent was obtained from all participants. All procedures followed were in accordance with the ethical standards of the responsible committee on human experimentation (institutional and national) and with the Helsinki Declaration of 1975, as revised in 2000 .

\section{Consent for publication}

Consent for publication was obtained from all patients for being included in the study.

\section{Competing interests}

The authors declare that they have no competing interests.

Received: 7 April 2021 Accepted: 30 August 2021

Published online: 16 September 2021

\section{References}

1. Lippel K, Lötters F. Public Insurance Systems: A Comparison of Cause-Based and Disability-Based Income Support Systems. In: Loisel P, Anema J, editors. Handbook of Work Disability. New York: Springer; 2013.

2. Collie A, Lane TJ, Hassani-Mahmooei B, Thompson J, McLeod C. Does time off work after injury vary by jurisdiction? A comparative study of eight Australian workers' compensation systems. BMJ Open. 2016;6(5):e010910. https://doi.org/10.1136/bmjopen-2015-010910.

3. Collie A, Sheehan L, Lane TJ, Gray S, Grant G. Injured worker experiences of insurance claim processes and return to work: a national, cross-sectional study. BMC Public Health. 2019;19(1):927. https://doi.org/10.1186/s12889-01 9-7251-x.

4. Knauf MT, Schultz IZ. Current conceptual models of return to work. In: Schultz I, Gatchel R, editors. Handbook of return to work: Springer; 2016. p. 27-51. https://doi.org/10.1007/978-1-4899-7627-7_2.

5. Schultz IZ, Chlebak CM, Stewart AM. Impairment, disability, and return to work. In: Schultz I, Gatchel R, editors. Handbook of return to work: Springer; 2016. p. 3-25. https://doi.org/10.1007/978-1-4899-7627-7_1.

6. Corbière $M$, Mazaniello-Chézol $M$, Bastien $M$, et al. Stakeholders' role and actions in the return-to-work process of workers on sick-leave due to common mental disorders: a scoping review. J Occup Rehabil. 2019;30(3): 381-419. https://doi.org/10.1007/s10926-019-09861-2.

7. Kilgour E, Kosny A, McKenzie D, Collie A. Interactions between injured workers and insurers in workers' compensation systems: a systematic review of qualitative research literature. J Occup Rehabil. 2015;25(1):160-81. https:// doi.org/10.1007/s10926-014-9513-x.

8. Young AE. Return to work stakeholders' perspectives on work disability. In: Loisel P, Anema J, editors. Handbook of work disability. Springer; 2013. p. 409-23. https://doi.org/10.1007/978-1-4614-6214-9_25.

9. Loisel $P$, Durand $M$, Berthelette $D$, et al. Disability prevention. Dis Manag Health Out. 2001;9(7):351-60. https://doi.org/10.2165/00115677-20010907000001.

10. MacEachen E, Clarke J, Franche R, Irvin E. Systematic review of the qualitative literature on return to work after injury. Scand J Work Environ Health. 2006:32(4):257-69. https://doi.org/10.5271/sjweh.1009.

11. Friesen MN, Yassi A, Cooper J. Return-to-work: the importance of human interactions and organizational structures. Work. 2001;17(1):11-22.

12. Mussener U, Svensson T, Soderberg E, Alexanderson K. Encouraging encounters: sick-listed persons' experiences of interactions with rehabilitation professionals. Soc Work Health Care. 2007;46(2):71-87. https:// doi.org/10.1300/J010v46n02_05.

13. Hubertsson J, Petersson IF, Arvidsson B, Thorstensson CA. Sickness absence in musculoskeletal disorders - patients' experiences of interactions with the Social Insurance Agency and health care. A qualitative study. BMC Public Health. 2011;11(107):107.

14. Ostlund G, Cedersund E, Alexanderson K, Hensing G. "It was really nice to have someone"--lay people with musculoskeletal disorders request 
supportive relationships in rehabilitation. Scand J Public Health. 2001; 29(4):285.

15. Müssener U, Ståhl C, Söderberg E. Does the quality of encounters affect return to work? Lay people describe their experiences of meeting various professionals during their rehabilitation process. Work. 2015;52(2):447-55. https://doi.org/10.3233/WOR-152121.

16. Müssener U, Festin K, Upmark M, Alexanderson K. Positive experiences of encounters with healthcare and social insurance professionals among people on long-term sick leave. J Rehabil Med. 2008;40(10):805-11. https:// doi.org/10.2340/16501977-0259.

17. Lynöe N, Wessel M, Olsson D, Alexanderson K, Helgesson G. Does feeling respected influence return to work? Cross-sectional study on sick-listed patients' experiences of encounters with social insurance office staff. BMC Public Health. 2013;13(1):268. https://doi.org/10.1186/14 71-2458-13-268

18. Grant GM, O'Donnell ML, Spittal MJ, Creamer M, Studdert DM. Relationship between stressfulness of claiming for injury compensation and long-term recovery: a prospective cohort study. JAMA Psychiatry. 2014;71(4):446.

19. Nordgren L, Söderlund A. Being on sick leave due to heart failure: self-rated health, encounters with healthcare professionals and social insurance officers and self-estimated ability to return to work. Psychol Health Med. 2015;20(5):582-93. https://doi.org/10.1080/13548506.2015.1007148

20. Nordgren L, Söderlund A. Being on sick leave due to heart failure: encounters with social insurance officers and associations with sociodemographic factors and self-estimated ability to return to work. Eur J Cardiovasc Nurs. 2016;15(3):27-36. https://doi.org/10.1177/147451 5115571033.

21. Olsson D, Alexanderson K, Bottai M. What positive encounters with healthcare and social insurance staff promotes ability to return to work of long-term sickness absentees? Scand J Public Health. 2016;44(1):91-7. https://doi.org/10.1177/1403494815608098.

22. Upmark M, Hagberg J, Alexanderson K. Negative encounters with social insurance officers-experiences of women and men on long-term sick leave. Int J Soc Welf. 2011;20(3):309-17. https://doi.org/10.1111/j.1468-2397.2009. 00702.x.

23. Vandenbroucke JP, Von Elm E, Altman DG, Gøtzsche PC, Mulrow CD, Pocock SJ, Poole C, Schlesselman JJ, Egger M \& Strobe Initiative. Strengthening the Reporting of Observational Studies in Epidemiology (STROBE): explanation and elaboration. PLoS Med. 2007;4(10):e297. https://doi.org/10.1371/journal. pmed.0040297.

24. FCP. Finnish Centre for Pensions. Persons insured for an earnings-related pension in Finland. Helsinki: Statistics from the Finnish Centre for Pensions 13/2020; 2019

25. The Service Network of Occupational Rehabilitation Charter Työhönkuntoutumisen palveluverkoston peruskirja. 2016.

26. Gould R, Härkäpää K, Järvikoski A. Toimiiko työeläkekuntoutus? Helsinki: Finnish Centre for Pensions. Studies; 2012

27. Thornthwaite L, Markey R. Return to work after workplace injury: injured workers, insurers and employers. Aust I Soc Issues. 2017;52(2):98-115. https://doi.org/10.1002/ajs4.11.

28. Ahlgren $\AA$, Bergroth A, Ekholm J, Schüldt K. Work resumption after vocational rehabilitation: a follow-up two years after completed rehabilitation. Work. 2007:28(4):343-54.

29. Fabrigar LR, Wegener DT, MacCallum RC, Strahan EJ. Evaluating the use of exploratory factor analysis in psychological research. Psychol Methods. 1999; 4(3):272-99. https://doi.org/10.1037/1082-989X.4.3.272.

30. Hoyle RH. Structural equation modeling: concepts, issues, and applications. Thousand Oakes: Sage Publications; 1995.

31. Netemeyer RG, Bearden WO, Sharma S. Scaling procedures issues and applications. Thousand Oaks: Sage Publications; 2003. https://doi.org/10.413 5/9781412985772.

32. Beardwood BA, Kirsh B, Clark NJ. Victims twice over: perceptions and experiences of injured workers. Qual Health Res. 2005;15(1):30-48. https:// doi.org/10.1177/1049732304268716.

33. Svensson T, Karlsson A, Alexanderson K, Nordqvist C. Shame-inducing encounters. Negative emotional aspects of sickness-Absentees' interactions with rehabilitation professionals. J Occup Rehabil. 2003;13(3):183-95. https:// doi.org/10.1023/A:1024905302323

34. Lippel K. Workers describe the effect of the workers' compensation process on their health: a Quebec study. Int J Law Psychiatry. 2007;30(4-5):427-43. https://doi.org/10.1016/j.jijp.2007.06.013.
35. Bloch FS, Prins R. Who returns to work \& why?: a six-country study on work incapacity \& reintegration. New Brunswick: Transaction publishers; 2001.

36. Marnetoft S-U, Selander J. Long-term effects of early versus delayed vocational rehabilitation -- a four-year follow-up. Disabil Rehabil. 2002;24(14): 741-5. https://doi.org/10.1080/09638280210124338.

37. Klanghed U, Svensson T, Alexanderson K. Positive encounters with rehabilitation professionals reported by persons with experience of sickness absence. Work. 2004;22(3):247-54.

38. Saarnio L. Työeläkekuntoutus vuonna 2015. In: Rehabilitation within the earnings-related pension system in 2015; 2016. Statistics from the Finnish centre for pensions 7/2016. ISSN 2343-3558.

39. Musil CM, Jones SL, Warner CD. Structural equation modeling and its relationship to multiple regression and factor analysis. Res Nurs Health. 1998;21(3):271-81. https://doi.org/10.1002/(SICI)1098-240X(199806)21:3< 271::AID-NUR10>3.0.CO;2-G.

\section{Publisher's Note}

Springer Nature remains neutral with regard to jurisdictional claims in published maps and institutional affiliations.

Ready to submit your research? Choose BMC and benefit from

- fast, convenient online submission

- thorough peer review by experienced researchers in your field

- rapid publication on acceptance

- support for research data, including large and complex data types

- gold Open Access which fosters wider collaboration and increased citations

- maximum visibility for your research: over $100 \mathrm{M}$ website views per year

At $\mathrm{BMC}$, research is always in progress.

Learn more biomedcentral.com/submissions 